\title{
A interface Internet/s@úde: perspectivas e desafios
}

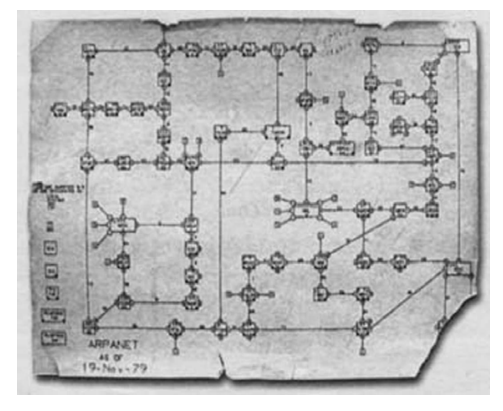

Luis David Castiel ${ }^{1}$

Paulo Roberto Vasconcellos-Silva ${ }^{2}$

CASTIEL, L. D.; VASCONCELLOS-SILVA, P. R. The interface He@lth/Internet: perspectives and challenges, Interface - Comunic, Saúde, Educ, v.7, n.13, p.47-64, 2003.

Information and communication technology (ICT) through the Internet are changed into elements, processes and objects produced in order to be used by human bio-sciences relating to the practice of BioMedicine, such as Public Health. ICT has been covering increasingly large fields of medical information, producing specialization sectors known as telemedicine, cyber-medicine and the so-called consumer healthcare information technology. It tries to meet consumers' information needs, by apparently creating something similar to self-treatment with some degree of expertise. In this way, consumers would be able to make more 'informed' decisions in terms of their purchases in the healthcare field. In order to attain this objective, computer programs have come up with decision aids software for healthcare and Web semantics have been created. The mingling of three powers that participate in the mechanisms that organize present-day life is clear - the predominance of instrumental reasoning and its techno-scientific production, the power created by the union of institutions and ideologies, and the belief in the myths, symbols and rites of scientific technology. As a possible result, we may see society colonized by an alliance between authorities that produce specialized knowledge, professionals that apply this knowledge to produce technological items or package them in technological wrappings, by industrial systems and by information, distribution and commercial networks.

KEYWORDS: Internet; computer science and Medicine; tele-medicine; health care; health promotion.

As tecnologias de informação e comunicação via Internet (TICs) são transformadas em elementos/processos/ objetos produzidos para serem utilizados no âmbito das tecnobiociências humanas, vinculadas tanto às práticas da Biomedicina como às da Saúde Pública. As TICs ocupam domínios cada vez mais abrangentes da informática médica, produzindo setores de especialização denominados e-saúde, telemedicina, cibermedicina e a chamada informática para a saúde do consumidor (ISC). A ISC, em especial, procura suprir as necessidades de informação de consumidores que, a princípio, poderiam fazer escolhas para aquisições mais bem informadas. Surgem programas computacionais para auxílio a decisões (decision aids' software) e a Web semântica. Percebe-se nesta situação, a imbricação de três sistemas: o predomínio da razão instrumental e suas produções tecnocientíficas; o poder enfeixado pela junção de instituições e ideologias; a crença na supremacia dos mitos, símbolos e ritos promovidos pela tecnociência. Como possível resultado, temos uma colonização da sociedade pela aliança entre autoridades geradoras de conhecimentos especializados, profissionais encarregados de produzi-los como objetos técnicos ou empacotá-los com invólucros tecnológicos, o conjunto do sistema industrial e as redes de comunicação, distribuição e consumo.

PALAVRAS-CHAVE: Internet; informática médica; telemedicina; assistência médica; promoção da saúde.

\footnotetext{
${ }^{1}$ Pesquisador, Departamento de Epidemiologia, Escola Nacional de Saúde Pública (ENSP)/FIOCRUZ.<castiel@ensp.fiocruz.br>

2 Professor, Departamento de Clínica Médica, Universidade do Rio de Janeiro; Médico e membro do Conselho de Editoração de Internet; Médico do Instituto Nacional do Câncer. <paulor@inca.org.br>
} 
Na edição de 5 de setembro de 2001 da Revista Veja (p. 64), em matéria intitulada 'A dor de nunca saber o bastante', de Cristiana Baptista, sobre a "angústia típica dos tempos atuais" devido aos efeitos psicológicos do excesso de informação, há um trecho que faz menção aos cybercondríacos, "pessoas que por meio de pesquisas sobre saúde na Internet descobrem informações que deveriam estar disponíveis apenas para médicos". Além disso, há declarações do infectologista do hospital paulista Albert Einstein, Artur Timerman, que considera ter se tornado rotineiro "atender pacientes que fazem pesquisa na Internet e, sem a menor base, querem palpitar no tratamento". Diz ele: "Sem um bom conhecimento prévio, a Internet é um caos que joga com a ignorância das pessoas" (Batista, 2001, p.64).

No Brasil, é difícil precisar a quantidade de sites ligados à saúde. Esta dificuldade pode ser ilustrada pela rápida pesquisa no tópico específico relativo à 'saúde' no Google. Foi obtida (em 15/05/2003) a indicação de 469.000 itens em língua portuguesa (inclui sites de Portugal e outros países de língua portuguesa) com as mais variadas origens, características, finalidades, temas, teores. No entanto, ao tentarmos acessá-los, vamos obter portais não mais existentes em um número considerável de casos.

Como introdução a questões desta ordem, ainda de modo preliminar, cabe indagar: qual a pertinência e as implicações das múltiplas facetas do complexo cenário na atualidade nas interseções saúde/meios eletrônicos de comunicação parcialmente representadas por estes breves comentários de abertura? Como é possível se orientar diante de diversas e eventualmente conflituosas perspectivas que emanam das inter-relações entre usuários/ consumidores/pacientes, portais de saúde (públicos e privados), páginas de profissionais/serviços responsáveis por assistência de variados tipos disponibilizando informações com distintos níveis de qualidade? Como dimensionar a confiabilidade da informação (e dos produtos e serviços apresentados) (Castiel \& Vasconcellos-Silva, 2002)?

Ora, todo projeto de ação, sobre o qual pairam incertezas sobre suas conseqüências, exige estratégias baseadas em informações dentro de um padrão de racionalidade econômica, ou seja, interessada na seleção de meios com previsão dos custos e benefícios daí derivados. A informação definidora de rumos no interior de incertezas é sempre desejável e valiosa, já que pode nortear nossas ações e neutralizar a ansiedade das indeterminações quanto aos efeitos das resultantes. De forma inversa, a informação que encerra contradições gera dubiedades, incertezas e temores de forma equivalente à falta ou ao excesso de informações.

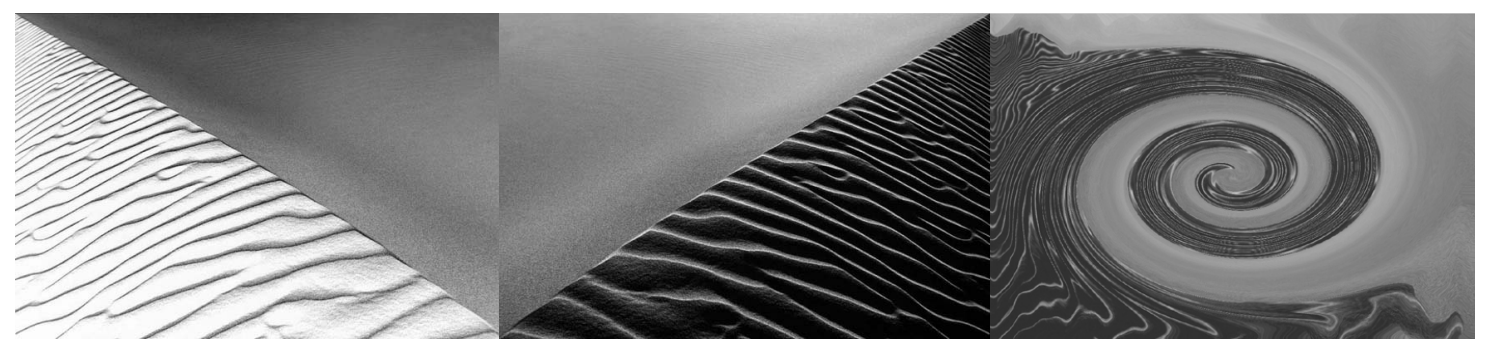


Comunicação virtual entre cuidadores e pacientes Voltemos à ilustração delineada no início da introdução, que consiste no uso de correio eletrônico entre médicos e pacientes. Há estudos que propõem protocolos éticos para lidar com problemas oriundos da recepção de mensagens

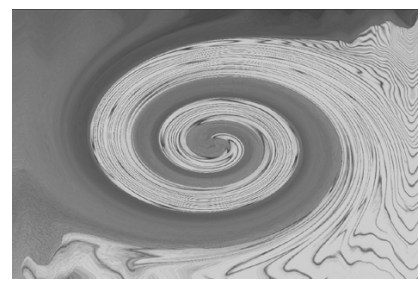
não-solicitadas de pacientes na ausência da relação médico-paciente preexistente (Eysenbach, 2000a).

Assim, construiu-se uma tipologia de modalidades de contatos: tipo B (relações bona fide), onde há uma relação médico-paciente preexistente (ou, então, que o paciente tenha tido um primeiro contato com o profissional de saúde em sua atividade prática, ou que este tenha tido acesso a seus dados médicos eletrônicos ou, ainda, que haja ocorrido uma consulta com tal médico); tipo A (ausência de relação médico-paciente prévia), onde as interações on-line carecem das características já descritas (a comunicação tende a ser impessoal, eventualmente anônima; mais informal, menos específica, mais acessível que pessoalmente). Exemplos: paciente envia uma mensagem não solicitada a um médico; serviços tipo 'pergunte ao doutor' na Internet; resposta de um médico a um pedido de aconselhamento público em uma homepage ou newsgroup.

Tais contatos possuem características e implicações distintas. Isto mostra as dificuldades de definir o estatuto do contato em cada contingência. Esta temática vem sendo alvo de estudos e proposições de princípios éticos para nortear tais contatos e evitar possíveis desdobramentos indesejáveis. $A$ priori, parece existir acordo quanto à necessidade de educar pacientes para indicar falhas deontológicas médicas em diagnosticar e tratar pela Internet, na ausência de relação médico-paciente de base (Eysenbach, 2000b). Ainda assim, são perceptíveis os enredamentos das novas questões midiáticas e a necessidade de maiores estudos e reflexões. Nesse sentido, no ano de 2001, a pesquisa da Harrisinteractive mostrou que $79 \%$ dos médicos entrevistados não veiculavam informações clínicas por e-mail, mas em torno da metade se disporia a fazê-lo se houvesse garantias de segurança $e$ privacidade. $O$ restante não o faria por razões outras que as citadas.

Telemedicina e Cibermedicina: apresentação de sites Se compararmos a incidência nos sistemas de busca bibliográfica biomédica Medline dos termos 'telemedicina' e 'cibermedicina' (em 15/05/2003), verificamos que o segundo (23 indicações, sendo 12 artigos de autoria de Eysenbach et al., 1999) está longe de possuir a presença do primeiro (5.627 referências em 15/05/2003) (PubMed). Ainda assim, há discussões conceituais com vistas a distinguir tais campos, apesar das assumidas superposições.

Wootton (2000) considera o termo 'telemedicina' como um guardachuva que engloba qualquer atividade médica envolvendo um elemento de distância. Creio ser importante explicitar que este autor é o editor da primeira revista acadêmica a abordar tais tópicos - justamente chamada Journal of Telemedicine and Telecare. Neste grau de generalidade, um tradicional telefonema entre médico e paciente poderia se abrigar sob este amplo guarda-chuva. Creio que a referência às modernas tecnologias 
comunicacionais é necessária para as tentativas de difícil circunscrição deste novo território. Apareceram outros termos que visam melhor definir o campo: tele-saúde (telehealth) e, mais recentemente, saúde on-line e e-saúde ( $e$ health).

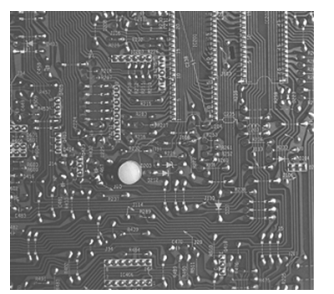

Um dos mentores da cibermedicina (Eysenbach et al., 1999) estabelece demarcações que, implicitamente, veiculam maior amplitude e alcance das modalidades ligadas à cibermedicina. De modo geral, as diferenças tendem a reproduzir especificidades que caracterizam a Medicina Diagnóstica/curativa e a Medicina Preventiva/Saúde Pública moderna, com ênfase na prevenção, promoção da saúde e autocuidado. Estes últimos aspectos assumiriam novas configurações ao envolverem predominantemente consumidores, dentro dos cânones do chamado projeto globalizante neoliberal.

Por sua vez, a informática da saúde do consumidor (ISC) surge como conseqüência da chamada cibermedicina dirigir-se para as necessidades de informação e de decisão de consumidores. A criação de uma suposta auto-expertise do consumidor que, a priori, teria como propósito funcionar como instrumento para escolhas mais informadas. Um dos emblemáticos exemplos da idéia moderna individualista dos consumidores de autocuidado pode ser percebida nas propostas de avaliação de risco em saúde da Sociedade da Medicina Prospectiva norte-americana e seu portal sintomaticamente denominado Youfirst. Ao acessarmos o sítio, descobrimos mais um elemento digno de nota: aparece no cabeçalho a grafia YouFirst ${ }^{\text {tm }}$, onde, como sabemos, a sigla sobrescrita indica tratar-se de marca registrada com sua devida legislação de proteção jurídica de propriedade privada.

$\mathrm{Na}$ página de abertura, temos uma sucinta apresentação que diz:

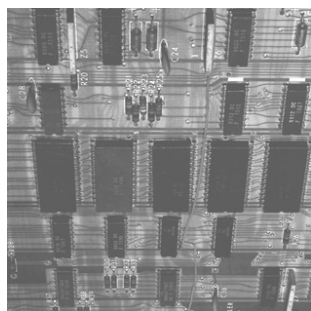

Você está sob o risco (risking) de morte precoce? Como o estresse, a falta de exercício, a nutrição deficiente, o alcoolismo, a hipertensão arterial, o colesterol elevado e a obesidade atingem seu bem-estar pessoal? Descubra como com uma avaliação de saúde pessoal grátis. ... Manter-se saudável significa cuidar de si próprio. Em outras palavras - colocando você em primeiro lugar. (Youfirst, 2003)

Submetidas as respostas ao portal, recebe-se uma computação do risco e são feitos relatórios com mensagens educativas individualizadas. Evidentemente, são explicitados alertas indicando que mesmo sendo a avaliação de risco à saúde (ARS) "extremamente útil para avaliar riscos à saúde de indivíduos e grupos, não são substitutos da história e do exame médico completo". Também, as ARSs não são apropriadas para todas as pessoas. Pessoas com doenças crônicas como câncer ou doença cardíaca, por exemplo, não obterão projeções acuradas de risco nestas áreas. Também, alguns bancos de dados populacionais excluem informações referentes a jovens e/ou idosos, em populações socioeconomicamente desfavorecidas (challenged) e em algumas minorias. Nestes casos, as ARSs 
podem não projetar acuradamente riscos para esses grupos (Youfirst).

A idéia de vigilância dos fatores de risco embute uma noção de possível procrastinação da morte para além de sua perspectiva radical, mediante sua 'fragmentação' em fatores de risco e correspondentes tentativas de controle destes virtuais, múltiplos e traiçoeiros componentes (Bauman, 2000). Não é despropositado pensar que o portal se volta primordialmente para indivíduos que se constituam, de fato, como potenciais consumidores de bens e serviços considerados protetores dos riscos. O portal não explica por que não se dirige a consumidores falhos, excluídos do acesso aos supostos benefícios da prevenção dos riscos em virtude de não disporem de condições econômicas necessárias e suficientes para atuarem efetivamente como agentes de consumo.

Ademais, começam a surgir programas de auxílio a decisões em questões de saúde que não substituem a ida ao médico (não se constituem em auxílios de acesso à informação!). Um deles se chama HouseCall, que produz um diagnóstico a partir dos sintomas dos usuários e da história médica pregressa (Eysenbach, 2000a).

Mas pouco se sabe como pacientes interagem com tais recursos. Como lidar com a possibilidade de estímulo à automedicação e a suposta proliferação de 'cybercondríacos'? No Brasil, temos o site Medicart, aparentemente sediado no estado do Paraná e sem indicar (pelo menos de modo visível) os responsáveis pelo portal (a única forma de identificar responsabilidades na visita ao portal, em maio de 2003, residia no nome, breve currículo e o respectivo registro em seu conselho do farmacêutico responsável pelas informações especializadas, técnicas e farmacológicas). Temos aí um exemplo de instrumento capaz de permitir tanto a pesquisa de preços comparativos entre medicamentos como a existência de similares $e$ genéricos.

De fato, o portal atua como se fosse um sintético dicionário de especialidades farmacêuticas com a característica de discriminar preços online. Na sua página de entrada, enfatiza os riscos da chamada automedicação e da mudança de medicamentos sem a devida consulta ao médico. Pretende desestimular a automedicação mas sugere trocadilho com a forma reflexiva do verbo 'medicar'... Se vale a analogia, estes alertas nos fazem lembrar os obrigatórios avisos dos malefícios do tabagismo que estão impressos nos maços de cigarros por determinação das autoridades governamentais de saúde. Pois, a estrutura do portal virtualmente (nos dois sentidos da expressão) constitui um potente veículo para aqueles que buscam a autoprescrição de medicamentos: o modo de acessar os produtos farmacêuticos e seus preços pode se dar por meio de designações químicas, dos nomes 'fantasia', das ações farmacológicas e da sintomatologia do paciente/consumidor. Dessa forma, o resultado da pesquisa gera configurações com estes quatro elementos, de modo a permitir a obtenção de supostas relações entre 'sinais/sintomas/diagnósticos', 'efeitos farmacológicos' e 'medicamento'.

Apesar de possíveis críticas metodológicas, em março de 2002 o site Harrisinteractive, em uma pesquisa (survey) por telefone, observou numa amostra de 707 pessoas de mais de 18 anos que, nos Estados Unidos, 110 
milhões de adultos vão em busca de informação de saúde na rede, em média três vezes por mês. Em 1998, eram 54 milhões, em 1999, 69 milhões, e em 2000, 97 milhões (Harrisinteractive, 2002).

Outro aspecto do projeto cibermédico se constituiria na criação/adoção de sistemas de acesso e armazenamento de dados de saúde de indivíduos. Poderiam, por exemplo, assumir a forma de smartcards que conteriam informações integradas sobre a saúde do seu possuidor passíveis, inclusive, de serem transferidas pela Internet. Ferramentas computacionais estão sendo desenvolvidas para auxiliar clínicos a conjugarem particularidades, preferências dos pacientes às questões clínicas e às restrições contextuais. Um aspecto crucial reside no acesso e controle dos pacientes sobre seus registros e também na confidencialidade da informação. É preciso conceber formas de reduzir a fragmentação dos registros médicos, ao permitir a agregação de dados provenientes de diferentes fontes com teores diversos (Mandl et al., 2001).

\section{Escolha do paciente baseada em evidências}

Uma outra forma de vincular Internet e saúde é constituída pela junção entre a ISC (informática da saúde do consumidor) e a MBE (Medicina baseada em evidências), sendo batizada como 'escolha do paciente baseada em evidências'. Curiosamente, neste momento, o termo 'consumidor' sai de cena sendo substituído pelo tradicional 'paciente'. Uma possível explicação seria a argumentação oferecida pelos autores desta vertente ser resultante da interseção entre a citada MBE (que enfatiza a necessidade de 'evidências cientificamente corretas' para intervenções em busca de efetividade) e a 'medicina centrada no paciente', cuja premissa essencial é: pacientes devem desempenhar papel central nas decisões sobre a assistência à sua saúde e de seus familiares. Tais informações podem ser divididas em: as específicas ao caso daquele paciente (diagnóstico, dados como faixa etária, gênero, condições gerais de saúde) e as de caráter generalizado, como, por exemplo, estatísticas de efetividade das distintas intervenções para a doença em foco.

Há diversas questões importantes envolvidas nesta temática, tais como os problemas de acessibilidade à linguagem médica, as formas de lidar com a incerteza, a ênfase na redução de custos etc., mas não é o propósito deste texto se deter nelas. Aqui, vamos comentar a aparente candura em meio ao tom supostamente caricatural com que se propõe a ascese do paciente/consumidor ao saber via e-saúde. Esta postura fica evidenciada na tipologia analógica ilustrada dos modelos de relação consumidor (que volta à cena) e profissional de saúde criada por Eysenbach (2001): paternalista - na qual o clínico, na 'terra sagrada dos conhecedores' (holy land of the knowing), está ao lado de um 'poço' vazio (o buraco da ignorância) para onde lança o medicamento em pílulas para um paciente prosternado no fundo do poço, dizendo como o mesmo deve ser ministrado e ordenando que não sejam feitas perguntas; educacional - onde o clínico anuncia que vai educar o paciente e lança para ele uma corda e este inicia uma subida pela parede (com a observação 'ex ducere conduzir para fora'); era Internet - o médico olha estupefato pacientes subindo para sair do poço pela escada de madeira $w w w$, através de self-support, uns galgando os ombros dos outros ou alçando-se mediante um balão e-mail, e o que conseguiu sair joga fora a tabuleta; consumidor como parceiro - o médico 


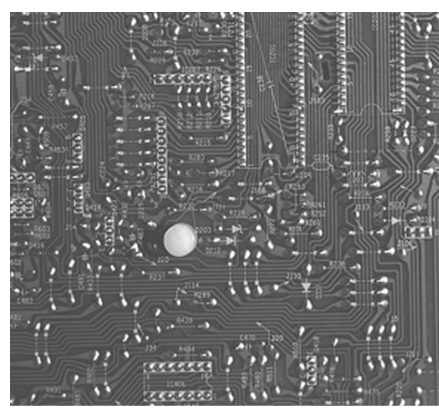

Circuito integrado recebe de mão estendida dizendo bem-vindo ao paciente que saiu pela sólida escada da educação do paciente via Internet. Aí, então, suas escolhas serão baseadas em evidências no contexto da medicina centrada no paciente.

De qualquer forma, há ensaios randomizados para mensurar a efetividade de programas (software) instrumentos de auxílio à decisão na assistência primária (primary care) no caso de reposição hormonal pós-menopausa, sem mediação pela Internet. Em geral, os resultados são considerados satisfatórios no que se refere à melhoria do conhecimento do paciente, à redução do conflito decisório e ao estímulo ao paciente desempenhar funções mais ativas na decisão sem aumentar sua ansiedade (Murray et al., 2001). Mas serão suficientes neste processo de decisão de caráter racional para não só 'orientar' o doente em suas escolhas cognitivas, mas também na esfera emocional? Será que pelo fato de não se produzirem nítidas evidências da importância de aspectos de caráter subjetivo/relacional (de mensuração problemática) não sejam relevantes? Como evidenciar os efeitos das manifestações de acolhimento por parte do profissional, dos signos de empatia entre as pessoas envolvidas na interação - que podem se manifestar, por exemplo, em uma conversa afável sobre educação de filhos? Apesar das contribuições das atividades técnicas na Medicina, que se procura basear em evidências, parece existir um exagero de busca de evidências na relação médico-paciente, em detrimento de tal relação.

\section{Psicoterapia via fluxo de elétrons}

Negroponte (1995) definiu o terreno das redes de comunicação, ou ciberespaço, como o "mundo dos fluxos de elétrons" em contraste com o "mundo dos átomos" no qual nascemos, crescemos, nos reproduzimos $e$ perecemos. Além da voragem e da obsolescência, caberia destacar o desapego da WEB ao mundo dos átomos, ao qual deveria oferecer seu suporte. Nos sítios se observam esparsas referências ao mundo não-virtual: poucos números de telefone, endereços, nomes de autores dos conteúdos, entre outros vínculos com o real. Tal desapego transposto para o terreno em questão, nos conduz à observação de fenômenos peculiares. Seriam possíveis trocas simbólicas plenas on line? Se possíveis, seriam consistentes?

A título de exemplo: a "terapia" on-line se tornou viável após o advento do IRC (Internet Relay Chat), um protocolo de comunicação na Internet que permite conversações on-line de grupos. Esta apropriação tecnológica parte do pressuposto de que uma terapia psicanalítica é, meramente, uma "conversa" em sua dimensão mais estreita: como trocas de informação. As vantagens aí conquistadas se ligam aos valores neoliberais mais caros: distância, dinheiro e tempo abreviados (além da privacidade do anonimato). O esforço de locomoção contemplaria os mais abúlicos. O custo das sessões poderia ser reduzido drasticamente, pois o terapeuta poderia economizar na montagem da estrutura de seu consultório virtual. Uma simples montagem de fundo - com uma estante repleta de livros de Freud ou um cenário neutro, bucólico e acolhedor bastariam. Pela ótica da doutrina da Comunicação Linear, os psicólogos e psiquiatras, ao contrário de outros profissionais da saúde, dispensariam o contato físico, já que suas intervenções ocorrem no campo simbólico. 
Por outro lado, alertam os críticos, os terapeutas não teriam contato presencial com seus entrevistados, o que é imprescindível no processo de percepção da linguagem corporal. Os entusiastas teriam a citar as facilidades dos videochats, e de aplicativos como o Microsoft NetMeeting (o que não é grande coisa no ponto atual de nosso desenvolvimento de transmissão de dados por via telefônica sem banda larga - esmagadora maioria dos usuários no Brasil). Além de alertar os usuários quanto aos riscos de um tipo de atividade no qual os responsáveis não se expõem diretamente, o Conselho Regional de Psicologia de São Paulo desaconselhou seus associados a adotar tal modalidade de atenção, baseado em sua questionável efetividade. Esta premissa da comunicação humana como sinônimo de transmissão de mensagens não é inédita nem recente como a Internet.

Web Semântica e Saúde

A profusão de páginas e sites desafiou os pesquisadores da indexação de informações, uma vez que a linguagem HTML e suas "tags" (anexos ocultos que definem a página e informam à máquina como esta vai ser exibida na tela) não permitem atribuir múltiplos desdobramentos semânticos à informação. A informação produzida para consumo na WEB é essencialmente unívoca, não admite múltiplas interpretações.

Até agora, a informação sempre foi produzida armazenada, localizada $e$ consumida por humanos. O objetivo das TICS é, obviamente, atender às pessoas e não às máquinas. Não obstante, se fosse possível reconstruir uma linguagem adequada à máquina, ou, como conceituam Berners-Lee et al. (2001), se adotarmos a idéia de "machine-understandable Information" chegaríamos bem perto da compreensão do conceito de WEB Semântica.

A Web Semântica se baseia essencialmente na descrição de denotações para alcançar variadas conotações no formato de dados e links que se enquadrem em ontologias criadas por peritos. Nas TICs, "ontologias" são categorias de elementos que descrevem uma determinada área de interesse, além de uma linguagem especializada em manipular as categorias destas representações. A idéia básica da WEB Semântica parte do princípio de que pelo acesso às ontologias, os browsers poderiam interpretar necessidades e recomendar aos usuários informação muito mais específica e adequada. Entretanto, cabe acrescentar que tais recomendações correm o risco de se repetir, o que limita a oferta aos usuários de outros conteúdos, conduzindo-os sempre aos mesmos temas.

Berners-Lee et al. (2001) afirmam que “...a WEB semântica não é uma Web à parte, mas uma sua extensão, na qual a informação é dada com sentidos semânticos bem definidos, o que aumenta a capacidade dos computadores de trabalharem em cooperação com as pessoas...". Para exemplificar, descrevem o caso de Pete e sua irmã Lucy, que buscam na Internet através de seus agentes (softwares que entram em contato com outros agentes para obter informações especificadas relevantes em outros sistemas), alternativas para a fisioterapia de sua mãe. Os agentes de Pete e Lucy conhecem, com base nos dados coletados à medida que foram sendo 
ativados, o endereço, os rendimentos e a agenda de seus usuários, o número do seguro-saúde de sua mãe, seu prontuário médico com várias informações sobre suas doenças, medicamentos usados, reações adversas etc.

A partir desses dados buscam na Web listas de profissionais credenciados, assim como os espaços em suas agendas. Por fim, oferecem uma lista de opções de escolha com base nas limitações de orçamento e qualificações em especialidades preliminarmente estabelecidas. Assim, Pete muda parte de seus compromissos, em coordenação com o agente e a agenda de Lucy, sua irmã. Ao apreender suas demandas, os agentes acumulariam as condições ideais tão ambicionadas por todos os empresários que pisaram neste planeta desde os primórdios do capitalismo:

1 A construção do perfil de consumo individual das pessoas (e não mais categorias de consumo segmentadas em faixas etárias, níveis de renda, padrões sócio educacionais etc.).

2 O privilégio da exposição e destaque de mercadorias e serviços no momento em que o usuário mais precisa deles - um estupendo avanço em relação às propagandas na TV (sob o ponto de vista dos que querem vender seus produtos). Ocorre um aproveitamento máximo das condições ideais de "vulnerabilidade" do consumidor, que consome itens e serviços em círculos viciosos impelidos por suas próprias "pulsões de consumo".

Como se pode perceber, as metas declaradas do projeto da Web Semântica são mais ambiciosas do que simplesmente permitir indexar melhor a informação da Web. Em sua proposta preliminar, são formas de fazer as máquinas compreenderem e assimilarem o mundo das demandas humanas para melhor atendê-las.

Uma questão: quem define as ontologias e em que bases? Se admitimos que a evolução da sociedade se dá pela via cognitiva, quem definirá em nosso nome as pequenas verdades que compõem as ontologias do mundo dos elétrons? Haverá pela primeira vez na história da Internet, uma regulamentação universal abrangente e ao mesmo tempo específica, que dedique espaço exclusivo às definições que propiciem o aprendizado coletivo? Será possível prever desdobramentos éticos nos atos conseqüentes a tais ontologias? A história da WEB e da Informática, de forma geral, nos demonstra que as grandes invenções nasceram e cresceram em berço acadêmico, mas reproduziram-se e proliferaram na selva do mercado, modificando-o e por ele sendo modificado. Um visão distópica mais próxima ao que observamos no cotidiano poderia ser descrita em bases não tão otimistas: Pete, que necessita de um fisioterapeuta para sua mãe, é um homem solteiro, na quinta década de vida. Percebe na mídia mensagens que dão conta da obesidade e das dislipidemias que predispõem ao risco de doenças cardiovasculares. Seu entendimento de dislipidemias não é muito preciso, porém o de obesidade lhe parece ser. É calvo e sente-se acima do peso, portanto, fisicamente pouco atraente em relação ao padrão estético dominante. A demanda de Pete é potencializada pela necessidade de preservação de sua saúde, mesclada à baixa auto-estima. Certa vez, encontrou em um site técnico sobre saúde a informação de que os homens calvos são mais predispostos a sofrer eventos coronarianos (por mecanismos relacionados aos hormônios masculinos). 
Desde então, passou a acessar sites sobre calvície e obesidade. Seu agente "apreendeu" que este é o foco capital de suas demandas no terreno da saúde. A cacofonia da mídia em nada contribuiu para esclarecê-lo. A WEB lhe potencializou o consumo de informações sobre "calvície e obesidade em homens de meia-idade solteiros". Sente-se solitário e seu padrão de renda the permite adquirir todas as inúmeras novidades oferecidas por seu agente. Seu microondas passaria a recusar todas os alimentos considerados calóricos demais. Suas compras nos supermercados on line seriam customizadas segundo suas cotas de calorias diárias.

Seu ambiente informacional seria assolado por inúmeros SPAMs (mensagens eletrônicas enviadas simultaneamente a milhares de usuários para divulgar produtos e serviços). Frente à frustração quanto aos resultados de suas buscas, o agente tutor de Pete passa, finalmente, a lhe oferecer links de psicoterapia on line. Os profissionais seriam selecionados, assim como os fisioterapeutas de sua mãe, segundo suas agendas e qualificações virtuais.

Epílogo: acumulam-se no apartamento de Pete aparelhos para exercícios abdominais que desafiam cientificamente seus depósitos de calorias, além de produtos para tratar a calvície - novos problemas de saúde pública no imaginário do homem urbano contemporâneo. Pete buscou $e$ encontrou precisamente aquilo que esperava da rede.

A qualidade da informação em saúde na rede Surge o considerável problema de controle de qualidade dos conteúdos relativos à saúde na Internet. Estudos da Rand elegeram dez instrumentos de busca de língua inglesa $e$ quatro em língua espanhola e buscaram informação sobre câncer de mama, asma infantil, depressão e obesidade.

Médicos investigaram a qualidade de informação em 25 websites. Em linhas gerais, vários sites continham informações contraditórias e/ou datadas e/ou incompletas em diversos aspectos de seus temas específicos. Mas, os elementos mais dignos de atenção são as questões relativas à compreensão dos receptores das informações (Feder \& Lyons, 2001).

Em termos globais, as preocupações quanto à qualidade da informação estão voltadas para: educar o consumidor, estimular a regulação dos emissores de informação em saúde, possuir instâncias não comprometidas para avaliar a informação e estabelecer sanções em casos de disseminação nociva ou fraudulenta de informação. Há alguns projetos de certificação e classificação da informação confiável em saúde na Internet como o MEDPics - plataformas de avaliação de conteúdos relacionados à Medicina na Internet (Eysenbach, 2000a) e o já citado TEAC-health (Rigby et al., 2001).

Existem, também, iniciativas voluntárias de códigos de conduta na rede (exemplos: American Medical Association, Internet Heath Coalition, Health Internet Ethics, Quackwatch - Your guide to health fraud, quackery and intelligent services e Health on the Net Foundation - HON).

Para efeitos deste trabalho, vamos enfocar esta última (a HON) como uma simplificada 'descrição de caso', destituída de pretensões metodológicas. A HON está sediada em Genebra e seu código de conduta dirige-se à padronização da confiabilidade da informação na rede, sem, no entanto, avaliar a qualidade de 
tal informação. Os portais que, em tese, seguem tais preceitos recebem o direito de exibir o selo de qualidade da HON. Os princípios, sinteticamente, são: 1) autoridade - profissionais treinados e qualificados serão responsáveis pela informação apresentada, a menos que seja declarado expressamente em caso disto não suceder; 2) complementaridade - a informação não substitui o relacionamento existente entre pacientes e respectivos profissionais; 3) confidencialidade - os dados disponibilizados por usuários serão mantido em sigilo (incluindo a identidade); 4) atribuições - quando for o caso, as informações terão a chancela de referências claras a fontes de consulta, inclusive indicando links para acesso a tais fontes. A data em que cada página médica foi atualizada deverá ser evidenciada; 5) justificativas similar ao anterior no que se refere a comprovar benefícios e resultados de tratamentos, produtos, serviços apresentados; 6) transparência na propriedade - os administradores visuais do portal devem apresentar claramente a informação e indicar endereços de contato para visitantes. $\mathrm{O}$ webmaster deverá exibir seu endereço eletrônico em todas as páginas; 7) transparência de patrocínio - os apoios (financeiros, materiais e de serviços) devem ser explicitados claramente, identificando, inclusive, as organizações comerciais e não-comerciais que tenham participado da construção do site; 8) honestidade da publicidade e da política editorial - deve ser claramente explicitado se a publicidade se constitui em fonte de renda do site. Os proprietários devem esclarecer sumariamente a política de divulgação empregada. Anúncios e publicidade devem ser diferenciados em seus contextos de apresentação dos conteúdos originais produzidos (HONcode, 2003). Alguns autores afirmam que a HON Foundation apresenta deficiências por não possuir verificação externa. E, portanto, está vulnerável a abusos, podendo proporcionar uma falsa impressão de segurança (Rigby et al., 2001).

Ademais, é interessante observar que esses portais assumem, de forma geral, dois dos três princípios de conduta que no nosso modo de ver estão em jogo nas questões da comunicação de conteúdos em saúde. A informação tem que ser correta, pertinente, adequada (princípio de correção), explícita quanto aos autores e patrocinadores (princípio ético). Entretanto, não se percebe menção a aspectos referentes à reflexão de questões básicas relativas aos processos de construção/difusão/consumo dos produtos tecnocientíficos, essencial para o exercício da crítica. Não notamos estes portais questionando o aumento dos preços de medicamentos, as debilidades das políticas públicas, a ênfase da mídia sobre aspectos 'selecionados' etc.

Até agora, aparentemente, ainda não é possível divisar com clareza como lidar satisfatoriamente com as questões relativas à avaliação da qualidade das informações de saúde disponibilizadas na rede. Dois relevantes trabalhos foram realizados por Jadad \& Gagliardi (1998; 2002). O primeiro mostrou que, em 1998, dos 47 instrumentos de avaliação da qualidade dos portais aparecendo em 'websites' oferecendo informação em saúde, 14 descreveram como foram desenvolvidos e cinco proporcionaram instruções para uso. Um segundo estudo, em 2002, procurou indicar se todos os sites de avaliação em 1998 ainda estavam operando. Foram identificados mais 51 novos 
instrumentos. Muitos dos instrumentos de avaliação do estudo original não mais estavam disponíveis. Destes 51 , somente cinco forneciam alguma informação que permitisse sua qualificação. Em relação aos seis sites localizados no primeiro estudo que permaneciam funcionando, nenhum desses instrumentos parecia ter sido validado. Como conclusão, os autores sinalizam que muitos instrumentos incompletos de avaliação da informação em saúde na rede continuam a aparecer. Muitos pesquisadores e organizações estão explorando formas de ajudar pessoas a procurar e a utilizar informação de qualidade confiável na rede. Mas, se tais informações são necessárias, efetivas ou sustentáveis ainda precisa ser demonstrado. (Jadad \& Gagliardi, 2002).

\section{A expansão caótica da WEB: a soma das máquinas e as sínteses dos humanos}

Desde o início da Modernidade, a faceta cultural sustentada pelo arcabouço científico nos tem protegido do medo ancestral do desconhecido. O que é externo ao conhecimento esclarecido e nos escapa pelas frestas da ciência, gera receios. O que não é racionalizável, nos amedronta pela impressão de sua intangibilidade pelo conhecimento científico. Ocorre que com o advento das TICs e o crescimento incremental do volume de "conhecimento relevante", acrescentou-se uma forma peculiar de receio pelo desconhecido. Com a expansão desmedida $e$ ininterrupta deste universo de informação ao longo do tempo, explicita-se, de forma cada vez mais reincidente, o receio da indeterminação das fronteiras geradas por este tipo de manancial.

Perante tamanha exposição a dados textuais e visuais nunca antes vista na história da humanidade, os desafios também se modificaram. Não obstante, uma proposta razoável para o problema da integração de informação com conhecimento no plano coletivo ainda está para ser formulada pelas TICs. Talvez esta não surja daí, uma vez que seus técnicos parecem estar mais ocupados na potencialização da capacidade das máquinas para transmitir e armazenar mais dados. É possível, mais do que nunca, manipular tais dados em formas cada vez mais sofisticadas, convencendo quanto à utilidade destes expedientes para os mais variados problemas que nunca tivemos. Em outras palavras, estes informatas parecem estar se dedicando inadvertidamente a agravar o problema, certos de que o volume disponível de informação, per se, irá levar, mediante um processo de 'seleção natural virtual', à evolução cognitiva do homo sapiens. A capacidade das máquinas de armazenar e apresentar informações há muito superou a potência cognitiva humana em sintetizá-las em conhecimento. Tal fenômeno não é recente, embora ultimamente tenha alcançado níveis paroxísticos, talvez por falta de crítica aos domínios que se sentem livres para nos inundar com dados sem qualquer compromisso com qualidade.

No campo movediço da saúde, nos deparamos freqüentemente com dados ambíguos e contradições, tanto no âmbito leigo como no técnico, nas encruzilhadas de variadas visões de mundo e distintos interesses. Tal avalanche de informações tende a nos saturar diante da 'erudição' do factual que nos distancia das sínteses essenciais. Neste terreno, como pesquisadores, são intensos nossos esforços em direção a conhecimentos verdadeiros pela busca criteriosa na rede das provas de sua existência (ou utilizando um termo 
traduzido da língua inglesa em voga - as evidências). Nas Ciências da Saúde, o enfoque individual tem procurado ancoramento para suas decisões abordando a dimensão do coletivo. No entanto, mesmo diante da cada vez mais ampliada disponibilidade de tecnologias de acesso a informações, ainda somos obrigados a nos contentar com possíveis e fugidias 'verdades pontuais', de acordo com as possibilidades e conveniências delimitadas pelas contingências.

Muitas vezes, sentimo-nos desgastados diante do vórtice informacional, onde se acoplam meios e mensagens, em uma poderosa sinergia geradora de compulsividades, tanto ligadas à impraticável atualização de conhecimentos, como na busca insaciável de orientações, preceitos, aconselhamentos, referências. Em especial aquelas dirigidas ao âmbito da saúde que, infelizmente, tendem, também, a perder sua validade. Basta ver como certas dietas alimentares são consideradas adequadas durante algum tempo, para depois serem substituídas por outras novidades, que superariam supostas falhas não detectadas das anteriores. Confundem-se relevâncias $e$ consistências.

Desafios na interface Internet/saúde: breves comentários finais Há esforços para amenizar a importante questão da 'divisão/brecha digital global' entre as populações informatizadas $e$ as despossuídas que tendem a ampliar as discrepâncias socioeconômicas. Mas as propostas tendem a ser primordialmente técnicas. Para além da falta de acesso dos desinformatizados (sem-hardware e/ou software e/ou web), é preciso levar em conta o fato de que estes recursos não foram concebidos, nem desenvolvidos pelos respectivos produtores de bens e serviços para tais grupos. Basta ver o idioma predominante na rede. Portanto, são mais desafiadores os problemas de aproximar culturalmente indivíduos desinformatizados às novas tecnologias e seus desdobramentos (Edejer, 2000).

Apesar disso, há valorosas e admiráveis iniciativas para enfrentar tais limitações. Um dos melhores exemplos não é governamental. Trata-se do Comitê para a Democratização da Informática, criado por Rodrigo Baggio, filho de um ex-executivo da IBM. Ele e sua equipe procuram locais de aula, treinam instrutores e fornecem computadores para favelas. Já recebeu auxílio de empresas nacionais e estrangeiras e dá consultoria em outros países.

Ademais, é perceptível a qualidade desigual da informação na rede, como aponta uma nova linha de estudos avaliativos, por exemplo, o dimensionamento da qualidade da informação na web sobre tratamento da depressão (Griffiths \& Christensen, 2000). O que dizer sobre nossos portais de saúde? Em nosso trabalho, à guisa de ilustração, destituída de rigor avaliativo, sinalizamos breves aspectos que sugerem a necessidade de 1 investigação nesta área.

No caso de informações sobre saúde, existem aspectos relativos a dimensões socioculturais e educacionais para decisões bem informadas. Estas envolvem entendimentos, nem sempre acessíveis, dos processos de construção dos conhecimentos tecnobiocientíficos na resolutividade de 
questões de saúde. Quais seriam os conteúdos básicos de epidemiologia e de estatística necessários para os indivíduos decidirem racionalmente acerca de medidas de autocuidado sobre dieta, exercício e não-tabagismo? Será que se trata de fornecer informação e técnicas de auxílio à decisão baseada em evidências? Estas condições podem ser necessárias, mas talvez não suficientes, se levarmos em conta dimensões não racionais, inconscientes que habitam a volição humana.

Em meio às tentativas de análise sobre a contemporaneidade (seja tecnófila, seja tecnófoba, seja tecnoambivalente), podemos visualizar a imbricação de três sistemas que participam da organização das configurações do mundo atual: o predomínio da razão instrumental e suas produções tecnocientíficas; o poder enfeixado pela junção de instituições e ideologias; a crença na supremacia dos mitos, símbolos e ritos promovidos pela tecnociência.

Como possível resultante deste cenário, presenciamos uma colonização da sociedade pela aliança entre geradores de conhecimentos especializados, especialistas que os produzem como objetos tecnológicos, o conjunto do sistema industrial (os macrossistemas técnicos) e as redes de comunicação, distribuição e consumo. Convivemos com excesso de imagens, textos e de escolhas possíveis. Uma das conseqüências palpáveis se constitui na ampliação de rupturas com as configurações simbólicas e com as mediações que regem as maneiras de ser em conjunto (Balandier, 1999).

No caso da saúde, temos a geração de uma sociedade de indivíduos que se reconfiguram sob a forma de protopacientes sem médicos, em consumidores de mercadorias/serviços ligadas tanto à informática como à pretendida proteção da saúde.

Baseando-nos em Cohn (2001), cabe aqui um comentário sobre a relação consumidor/cidadão/indivíduo: nos países economicamente mais fortes, as políticas sociais proporcionaram maior igualdade no interior de suas sociedades, por meio dos chamados welfare states. Apesar de seus atuais 'encolhimentos' a partir dos ditames neoliberais e das crises fiscais, foi aí que se constituíram e se estabeleceram os direitos de cidadania. Estes, de fato, não vieram separados do movimento de afirmação do próprio estatuto do ser 'cidadão', viabilizado pelas inerentes condições socioculturais e políticas de seus contextos socioculturais. Assim, tais cidadãos ocupariam criteriosamente seu lugar de consumidores bem informados que lidariam com as injunções do mercado de forma mais autônoma, pois estariam cientes de seus direitos.

Porém, como indica Bauman (2000), em função do inexorável processo de individualização contemporâneo (como mencionado no início do texto), o indivíduo se constitui como um vetor de desgaste e fragmentação para o cidadão. O primeiro usufrui da liberdade pessoal de escolha, inclusive para consumir como melhor lhe aprouver, descrente, indiferente, ou, na melhor das hipóteses, cauteloso quanto a participar de ações efetivas dirigidas ao 'bem comum'. Já o segundo buscaria seu próprio bem-estar pelo bem-estar da 'cidade'. Por mais resultados favoráveis que proporcionem, a busca de interesses comuns dos cidadãos é vista, no limite, como restrição à liberdade de escolha pessoalizada por parte do indivíduo de direito. Mas, para este se tornar um indivíduo de fato, é imperioso que se torne antes cidadão.

Enfim, inegavelmente, vivemos no Ocidente, com variações conforme as 
características das distintas formações sociais, políticas e econômicas, em situações hipermediatizadas - sociedades de indivíduos submetidos à nova trindade: informação, comunicação, técnica. Como assinala Balandier (1999), somos todos cada vez mais pertencentes à categoria Homo cathodicus, seres mediados por teclas e telas. Nestas circunstâncias, proliferam informações nem sempre congruentes e, também, aumentam as incertezas e as ansiedades diante desta saturação de possibilidades.

Apesar da importância atribuída à faceta libertária e democratizante da Internet, são necessários pré-requisitos tecnoculturais para acessá-la. Vale retomar a discussão de Sousa-Santos (2000) sobre a dupla ruptura epistemológica entre conhecimento científico e senso comum: a primeira se dá quando a ciência se diferencia do senso comum, a segunda consistiria em romper com a primeira para transformar o conhecimento científico em um novo senso comum. Mas que este não se torne regulatório e sim emancipatório. Então, como as estratégias comunicacionais viabilizadas pelos objetos tecnocientíficos nos permitiriam sair do senso comum conservador e chegar ao conhecimento emancipatório, aquele que não recusa a tecnologia, inclusive a utiliza para aceder ao "autoconhecimento ... e traduzir-se em sabedoria de vida"? Para isto, o referido autor detalha os elementos de uma "epistemologia dos conhecimentos ausentes" no interior de uma "epistemologia da visão" que lida com a tensão entre as facetas regulatórias e emancipatórias do conhecimento (Sousa-Santos, 2000, p.248). Aí, o sociólogo luso aponta a necessidade de prudência com vistas a perceber e controlar a maior insegurança, especialmente nos grupos oprimidos, excluídos, vulneráveis da sociedade e que mais se beneficiariam de práticas emancipatórias.

Se, por um lado, são visíveis as manifestações de descontrole da técnica tais como se observa: na proliferação de sites que difundem pedofilia, nazifascismo, anorexia nervosa, que ensinam processos químicos e técnicas laboratoriais para a produção de psicofármacos (como o ecstasy), ou mesmo artefatos explosivos etc; na criação incessante de novos e virulentos vírus de computador, (transgressões da técnica contra si própria); no recrudescimento e ampliação do terrorismo fundamentalista que utilizou a web em suas comunicações, fato que gerou restrições e controle do fluxo de mensagens da rede.

Por outro lado, é preciso assumir os indiscutíveis benefícios da inovação, da produção e da eficácia dos recursos tecnobiocientíficos no âmbito da saúde: vacinas, fármacos mais potentes, equipamentos médicos para aumentar a acurácia do diagnóstico, tratamento e reabilitação. São evidentes os efeitos em termos de aumento da longevidade e nas tentativas de procrastinação dos efeitos do envelhecimento para aqueles capazes de atuar como agentes de consumo.

A disponibilização de dados e de programas computacionais de auxílio à decisão via Internet pode ampliar o acesso das populações a informações sobre cruciais questões da vida e da saúde. Pode, também, ajudar a reduzir desgastes e ansiedades decorrentes das incertezas que se insinuam nas práticas de saúde, tanto no lado do profissional como no daquele que necessita de cuidados, não obstante o nome ou papel que se lhe atribua. 
Sem dúvida, é importante o estudo de usos da informática em saúde e respectivos riscos conforme a inadequação dos contextos de comunicação $e$, também, acerca das dificuldades de regulamentação consistente diante de temas relativos à saúde na rede. Mas, sobretudo, mesmo com os problemas decorrentes da individualização, ainda é essencial que se criem condições de aproximação entre os estatutos de cidadão e de consumidor ( $e$ de conhecimentos regulatório e emancipatório) em sociedades profundamente iníquas como a nossa.

\section{Referências}

BALANDIER, G. O dédalo. Para finalizar o século XX. Rio de Janeiro: Bertrand Brasil, 1999.

BAPTISTA, C. A dor de nunca saber o bastante. Veja, n.1716, p.62-6, 2001.

BAUMAN, Z. Modernidade líquida. Rio de Janeiro: Zahar Editora, 2000.

BERNERS-LEE, T.; HENDLER, J.; LASSILA, O. The Semantic Web. A new form of Web content that is meaningful to computers will unleash a revolution of new possibilities, 2001. Disponível em: <http:// www.sciam.com/article.cfm?articleID=00048144-10D2-1C70-84A9809EC588EF21>. Acesso em: 14 abr. 2003.

CASTIEL, L. D.; VASCONCELLOS-SILVA, P. R. Internet e o autocuidado em saúde: como juntar os trapinhos? Hist., Ciênc., Saúde - Manguinhos, v.9, n.2, p.291-314, 2002.

COHN, A. Saúde e democracia: o resgate da política. In: CONGRESSO PAULISTA DE SAÚDE PÚBLICA, 7. ., Santos, 2001. Resumo... Santos, 2001, p.12-9.

EDEJER, T. T. Disseminating health information in developing countries: the role of Internet. BMJ, n.321, p.797-800, 2000.

EYSENBACH, G. Consumer health informatics. BMJ, n.320, p.1713-6, 2000a.

EYSENBACH, G. Towards ethical guidelines for dealing with unsolicited patients emails and giving teleadvice in the absence of a pre-existing patient-physician relationship - systematic review and expert survey, 2000b. J. Med. Internet Res., v.2, n.1. Disponível em: <http://www.jmir.org/2000/1/e1/>. Acesso em 14 abr. 2003.

EYSENBACH, G.; DIEPGEN, T. L. The role of e-health and consumer health informatics for evidence-based patiente choice in the 21st century'. Clin. Dermatol., n.19, p.11-7, 2001.

EYSENBACH, G.; SA, E. R.; DIEPGEN, T. L. Shopping around the Internet today and tomorrow: towards the millenium of cybermedicine. BMJ, n.319, p.1294-6, 1999.

FEDER, B.; LYONS, J. S. Study gives mixed reviews to health sites on Web Online medical informations can be uneven, hard to find, 2001. Disponivel em: <http://www.siliconvalley.com/docs/news/depth/ health052301.htm>. Acesso em 12 dez. 2002.

GRIFFITHS, K. M.; CHRISTENSEN, H. Quality of web based information on treatment of depression: cross sectional survey. BMJ, n.321, p.1511-5, 2000.

JADAD, A. R.; GAGLIARDI, A. Rating health information on the Internet: navigating to knowledge or to Babel? JAMA, n.279, p.611-4, 1998.

JADAD, A. R.; GAGLIARDI, A. Examination of instruments used to rate quality of health information on the Internet: chronicle of a voyage with an unclear destination. BMJ, n.324, p.569-73, 2002.

MANDL, K. D.; SZOLOVITS, P.; KOHANE, I. S. Public standards and patients control: how to keep electronic, medical records accessible but private. BMJ, n.322, p.283-6, 2001. 
MURRAY, E.; DAVIS, H.; TAI, S. S.; COULTER, A.; GRAY, A.; HAINES, A. Randomised controlled trial of an interactive multimedia decision aid on hormone replacement therapy in primary care. BMJ, n.323, p.490-3, 2001.

NEGROPONTE, N. A vida digital. São Paulo: Companhia das Letras, 1995.

RIGBY, M.; FORSSTRÖM, J.; ROBERTS, R.; WYATT, J. Verifying quality and safety in health informatics services. BMJ, n.323, p.552-6. 2001.

SOUSA-SANTOS, B. A crítica da razão indolente. Contra o desperdício da experiência. Para um novo senso comum. A ciência, o direito e a política na transição paradigmática. São Paulo: Cortez, 2000. v.1.

WOOTTON, R. Recent advances: Telemedicine. BMJ, n.323, p.557-60, 2000.

\author{
Sites consultados \\ <http://www.harrisinteractive.com/news/ \\ index.asp?NewsID=237\&HI_election=All>. Acesso em 08 mai. 2003. \\ <http://www.google.com.br>. Acesso em 08 mai. 2003. \\ <http://www.ncbi.nlm.nih.gov/entrez/query.fcgi?CMD=search\&DB=PubMed>. \\ Acesso em 08 mai. 2003. \\ <http://www.youfirst.com/about.asp>. Acesso em 08 mai. 2003. \\ <http://www.medicart.com.br>. Acesso em 08 mai. 2003. \\ <http://www.hon.ch/HONcode/Portuguese/>. Acesso em 08 mai. 2003.
}

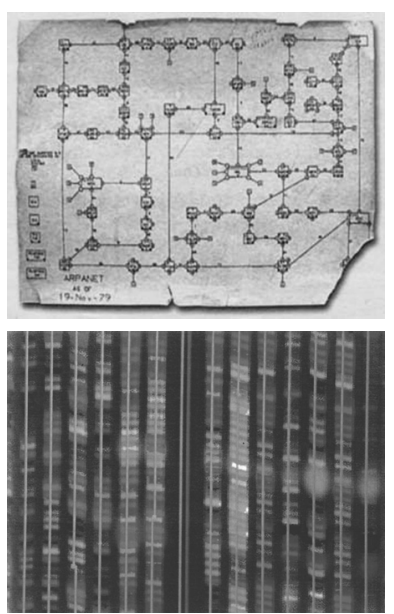

CASTIEL, L. D.; VASCONCELLOS-SILVA, P. R. Interfaz Internet/s@lud: perspectivas y desafíos, Interface - Comunic, Saúde, Educ, v.7, n.13, p.47-64, 2003.

Las tecnologías de información y comunicación vía Internet (TIC) son transformadas en elementos/procesos/objetos producidos para ser utilizados en el ámbito de las tecnobiociencias humanas, vinculadas tanto a las prácticas de la Biomedicina como a las de la Salud Pública. Las TIC ocupan dominios cada vez más abarcadores de la informática médica, produciendo sectores de especialización denominados e-salud, telemedicina, cibermedicina y la llamada informática para la salud del consumidor (ISC). La ISC, en especial, busca suplir las necesidades de información de los consumidores, que podrían hacer elecciones para adquisiciones, en principio, mejor informados. Surgen programas computacionales para ayuda a decisiones ('decision aids' software) y la Web semántica. Se percibe en esta situación la imbricación de tres sistemas: el predominio de la razón instrumental y sus producciones tecnocientíficas; el poder hacinado por la unión de instituciones e ideologías; la creencia en la supremacía de los mitos, símbolos y ritos promovidos por la tecnociencia. Como posible resultante tenemos una colonización de la sociedad por la alianza entre autoridades generadoras de conocimientos especializados, profesionales encargados de producirlos como objetos técnicos o empaquetarlos con envolturas tecnológicas, el conjunto del sistema industrial y las redes de comunicación, distribución y consumo.

PALABRAS CLAVE: internet; informática médica; telemedicina; asistencia médica; promoción de la salud. 
CASTIEL, L. D.; VASCONCELLOS-SILVA, P. R.
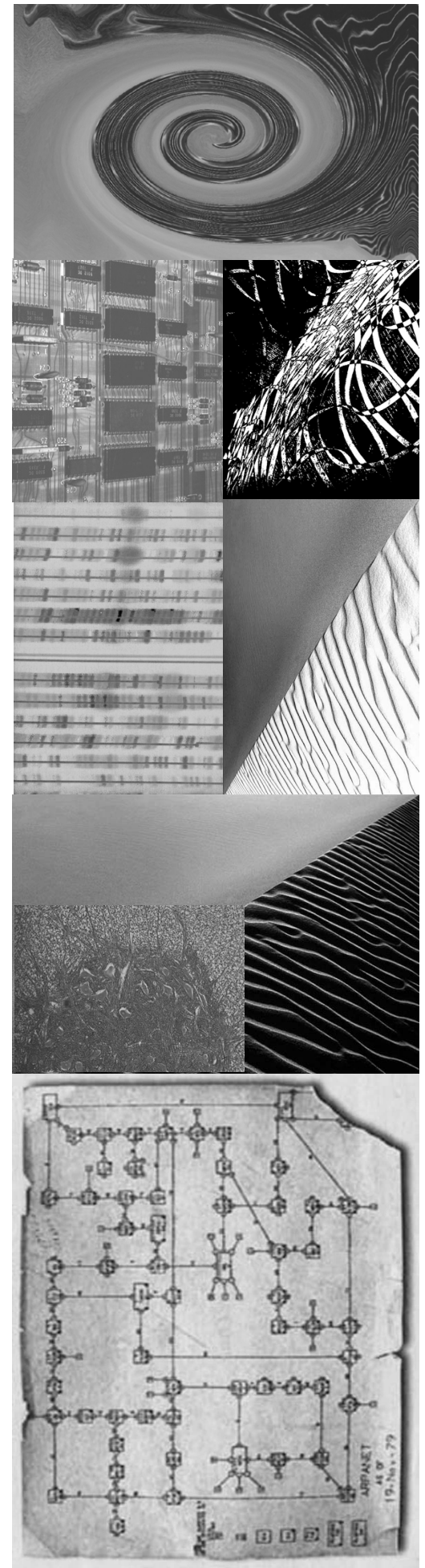

64 Interface - Comunic, Saúde, Educ, v7, n13, p.47-64, ago 2003 